\title{
Episodic coronary artery vasospasm and hypertension develop in the absence of Sur2 $\mathrm{K}_{\mathrm{ATP}}$ channels
}

\author{
William A. Chutkow, ${ }^{1}$ Jielin $\mathrm{Pu},{ }^{2}$ Matthew T. Wheeler, ${ }^{3}$ Tomoyuki Wada, ${ }^{2}$ \\ Jonathan C. Makielski, ${ }^{2}$ Charles F. Burant, ${ }^{4}$ and Elizabeth M. McNally ${ }^{5}$
}

\author{
${ }^{1}$ University of Chicago, Department of Medicine, Section of Cardiology, Chicago, Illinois, USA \\ ${ }^{2}$ University of Wisconsin-Madison, Department of Medicine, Cardiovascular Division, Madison, Wisconsin, USA \\ ${ }^{3}$ University of Chicago, Department of Molecular Genetics and Cell Biology, Chicago, Illinois, USA \\ ${ }^{4}$ University of Michigan, Department of Internal Medicine, Endocrinology and Metabolism Division, \\ Ann Arbor, Michigan, USA \\ ${ }^{5}$ University of Chicago, Department of Human Genetics, Chicago, Illinois, USA
}

\begin{abstract}
$\mathrm{K}_{\mathrm{ATP}}$ channels couple the intracellular energy state to membrane excitability and regulate a wide array of biologic activities. $\mathrm{K}_{\mathrm{ATP}}$ channels contain a pore-forming inwardly rectifying potassium channel and a sulfonylurea receptor regulatory subunit (SUR1 or SUR2). To clarify the role of $\mathrm{K}_{\mathrm{ATP}}$ channels in vascular smooth muscle, we studied Sur2 gene-targeted mice $\left(\right.$ Sur $\left.^{-l^{-}}\right)$and found significantly elevated resting blood pressures and sudden death. Using in vivo monitoring, we detected transient, repeated episodes of coronary artery vasospasm in Sur2 $2^{-/-}$mice. Focal narrowings in the coronary arteries were present in Sur2 $2^{-/-}$mice consistent with vascular spasm. We treated Sur2 $2^{-/-}$mice with a calcium channel antagonist and successfully reduced vasospastic episodes. The intermittent coronary artery vasospasm seen in Sur2 $2^{-/}$mice provides a model for the human disorder Prinzmetal variant angina and demonstrates that the SUR2 $\mathrm{K}_{\mathrm{ATP}}$ channel is a critical regulator of episodic vasomotor activity.
\end{abstract}

This article was published online in advance of the print edition. The date of publication is available from the JCI website, http://www.jci.org. J. Clin. Invest. 110:203-208 (2002). doi:10.1172/JCI200215672.

\section{Introduction}

$\mathrm{K}_{\mathrm{ATP}}$ channels respond to changes in the intracellular ATP content by altering a cell's membrane potential (1, 2 ). $K_{\text {ATP }}$ channels are widely expressed in neural, endocrine, and muscle tissues where they are inhibited by ATP and stimulated by ADP. $\mathrm{K}_{\mathrm{ATP}}$ channels are an octameric complex consisting of four potassium channel subunits, either Kir6.1 or Kir6.2, and four sulfonylurea receptor subunits, SUR1 or SUR2 (3-9). SURs, named for their ability to bind with high affinity the hypoglycemic sulfonylurea agents, are members of the ATP-binding cassette $(\mathrm{ABC})$ transporter family of transmembrane proteins. SUR1 and SUR2 are 70\% identical proteins encoded by different genes. SUR2 undergoes differential splicing altering its carboxy-terminal 42 amino acids, yielding channels with unique pharmacologic properties.

In cardiomyocytes, where $\mathrm{K}_{\mathrm{ATP}}$ channels modulate protection from ischemia, SUR1 and SUR 2 are coexpressed

Received for publication April 12, 2002, and accepted in revised form May 29, 2002

Address correspondence to: Elizabeth M. McNally, Section of Cardiology, University of Chicago, 5841 South Maryland Avenue, MC 6088, Chicago, Illinois 60637, USA. Phone: (773) 702-2672; Fax: (773) 702-2681;

E-mail: emcnally@medicine.bsd.uchicago.edu.

Conflict of interest: No conflict of interest has been declared. Nonstandard abbreviations used: ATP-binding cassette (ABC); sulfonylurea receptor subunit (SUR); electrocardiogram (ECG); mean arterial blood pressure (MAP).
$(10,11)$. In smooth muscle and voluntary striated muscle, only SUR2 is expressed (11). The physiology and pharmacology of $\mathrm{K}_{\mathrm{ATP}}$ channels have been most extensively studied in the pancreatic $\beta$ cell. Here, sulfonylurea agents such as glibenclamide inhibit $\mathrm{K}_{\mathrm{ATP}}$ channels by binding to SUR1, which results in the closure of the channel and the stimulation of insulin release (3). In vascular smooth muscle, potassium channel openers, such as nicorandil, implicate $K_{\text {ATP }}$ channels in the regulation of tonic vasomotor activity. These agents, useful in the treatment of hypertension and angina, open $\mathrm{K}_{\text {ATP }}$ channels leading to potassium efflux, membrane hyperpolarization, and vasodilation (12-14). Potassium channel openers alter membrane potential through $\mathrm{K}_{\mathrm{ATP}}$ channels and thereby activate voltage-dependent calcium channels producing changes in vascular smooth muscle contractility (15). In skeletal muscle, $\mathrm{K}_{\text {ATP }}$ channels affect glucose metabolism. Using mice with a targeted disruption of the Sur2 gene (16), we demonstrated that the loss of $\mathrm{K}_{\mathrm{ATP}}$ channels increased insulin responsiveness mediated by striated muscle.

The diversity of responses to individual pharmacologic agents that act through $\mathrm{K}_{\mathrm{ATP}}$ channels derives in part from the tissue-specific expression of $\mathrm{K}_{\mathrm{ATP}}$ subunits and the composition of $\mathrm{K}_{\mathrm{ATP}}$ channels within a cell. Since pharmacologic agents act through the SUR subunit, the significant homology between SUR isoforms and their overlapping expression pattern complicates the interpretation of pharmacologic studies in 
vivo. To better understand the potential role of $\mathrm{K}_{\mathrm{ATP}}$ channels in the vascular smooth muscle physiology, we studied mice with a targeted disruption of the Sur2 gene (Sur2 $\left.{ }^{-/}\right)$(16). We observed elevated resting blood pressure in Sur2 $2^{-/-}$mice and found that Sur2 $2^{-/}$displayed sudden death from ST segment elevation and coronary artery vasospasm. Furthermore, we inhibited ST segment elevation with nifedipine, a calcium channel antagonist. These data highlight the importance of the vascular smooth muscle $\mathrm{K}_{\mathrm{ATP}}$ channel in the tonic and episodic regulation of vasomotor tone.

\section{Methods}

Telemetric blood pressure monitoring. Blood pressure recordings were performed in conscious, freely mobile adult mice (12-16 weeks). Surgical anesthesia was achieved with inhaled isoflurane (Sigma-Aldrich, St. Louis, Missouri, USA) (1.5\% mixture with $0_{2}, 1 \mathrm{l} / \mathrm{min}$ flow through nose cone; VetEquip Inc., Pleasanton, California, USA). Gel-tipped pressure-transducing catheters connected to implantable radio transmitters (TA11PA-C20; Data Sciences International, St. Paul, Minnesota, USA) were used to cannulate the left carotid artery and were sutured into position. Continuous recordings were made during nonfeeding hours $(8 \mathrm{am}-8 \mathrm{pm})$ starting at postoperative day 2. Alternatively, recordings were made under general anesthesia with intravenous infusions of various agents, as described below.

Intravenous drug infusions. Jugular veins were cannulated with PE-10 tubing connected to a triple port adapter. Each port was connected to a 5-cc syringe pump (Harvard Apparatus Co., Holliston, Massachusetts, USA) set to infuse at $10 \mu \mathrm{l} / \mathrm{min}$. The left carotid artery was cannulated with a TA11PA-C20 pressure-transducer catheter, as described above. Drugs were infused at a rate of $10 \mu \mathrm{l} / \mathrm{min}$. Pinacidil (Sigma-Aldrich) was administered at a rate of $5 \mu \mathrm{g} / \mathrm{kg} / \mathrm{min}$ and glibenclamide (SigmaAldrich) at $100 \mu \mathrm{g} / \mathrm{kg} / \mathrm{min}$. Infusions and recordings were made under $1.5 \%$ isoflurane-inhaled anesthesia.

Cell isolation. Single smooth muscle cells were isolated from the mouse aorta by a modified method described by Sturek et al. (17). Briefly, the thoracic aorta was resected and put into ice-cold physiological buffer consisting of $135 \mathrm{mM} \mathrm{NaCl}, 5 \mathrm{mM} \mathrm{KCl}, 1 \mathrm{mM} \mathrm{MgCl} 2,0.44 \mathrm{mM}$ $\mathrm{NaH}_{2} \mathrm{PO}_{4}, 0.34 \mathrm{mM} \mathrm{Na}_{2} \mathrm{HPO}_{4}, 2.6 \mathrm{mM} \mathrm{NaHCO} 3,2 \mathrm{mM}$ HEPES, and $10 \mathrm{mM}$ glucose, pH 7.4 (with $\mathrm{NaOH}$ ). After removing connective tissue, the aorta was opened, endothelium removed, cut into 1 - to 2 -mm pieces, and incubated in an enzymatic solution, which was the buffer above with $1 \mathrm{mg} / \mathrm{ml}$ papain, $1.5 \mathrm{mg} / \mathrm{ml}$ dithiothreitol, 2 $\mathrm{mg} / \mathrm{ml}$ collagenase type IV (Worthington Biochemical Corp., Lakewood, New Jersey, USA), 0.9 U/ml type I elastase (liquid type; Sigma-Aldrich), $1 \mathrm{mg} / \mathrm{ml} \mathrm{BSA}, 2 \mathrm{mg} / \mathrm{ml}$ hyaluronidase (Sigma-Aldrich), $0.25 \mathrm{mM} \mathrm{Ca}$, for $20-30$ minutes at $37^{\circ} \mathrm{C}$. Cells were stored in physiological buffer no longer than 6-8 hours during the study.

Electrophysiology and data analysis. Conventional patchclamp whole-cell recording was used at $20-22^{\circ} \mathrm{C}(18)$. Axopath 200B amplifier and pClamp version 7.0 software
(Axon Instruments Inc., Union City, California, USA) were used. Patch pipettes were drawn from borosilicate glass (World Precision Instruments Inc., Sarasota, Florida, USA) with a resistance of 1-2 M $\Omega$ when filled with recording solutions. The bath solution contained $4 \mathrm{mM}$ $\mathrm{KCl}, 140 \mathrm{mM} \mathrm{NaCl}, 10 \mathrm{mM}$ HEPES, $1 \mathrm{mM} \mathrm{CaCl}_{2}, 10 \mathrm{mM}$ glucose, $1.2 \mathrm{mM} \mathrm{MgCl}_{2}$, and $50 \mu \mathrm{M}$ nifedipine, $\mathrm{pH} 7.4$, with $\mathrm{NaOH}$. Nifedipine was added to the bath solution to block the L-type $\mathrm{Ca}^{2+}$ current. The pipette solution was composed of $140 \mathrm{mM} \mathrm{KCl}, 20 \mathrm{mM}$ HEPES, $5 \mathrm{mM}$ EGTA, $2 \mathrm{mM} \mathrm{MgCl}_{2}, 1 \mathrm{mM}$ UDP, $\mathrm{pH} 7.25$, with KOH. To ensure the opening of two types of $\mathrm{K}_{\mathrm{ATP}}$ channels reported in smooth muscle cells $(8,19)$, ATP was omitted and $\mathrm{Mg}$ and UDP were included in the pipette. The whole cell current was generated by clamp pulses from a holding potential of $-70 \mathrm{mV}$ to voltages ranging from -90 to 10 $\mathrm{mV}$ in $20-\mathrm{mV}$ steps for $235 \mathrm{~ms}$. The currents were filtered at $1 \mathrm{kHz}$ and sampled at $5 \mathrm{kHz}$. Data were digitally stored for the off-line analysis using pClamp 6 software (Axon Instruments Inc.). Whole cell currents usually reached maximal levels 2 minutes after membrane rupture.

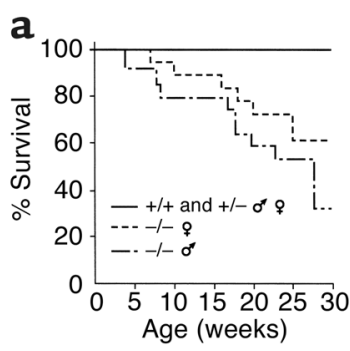

b
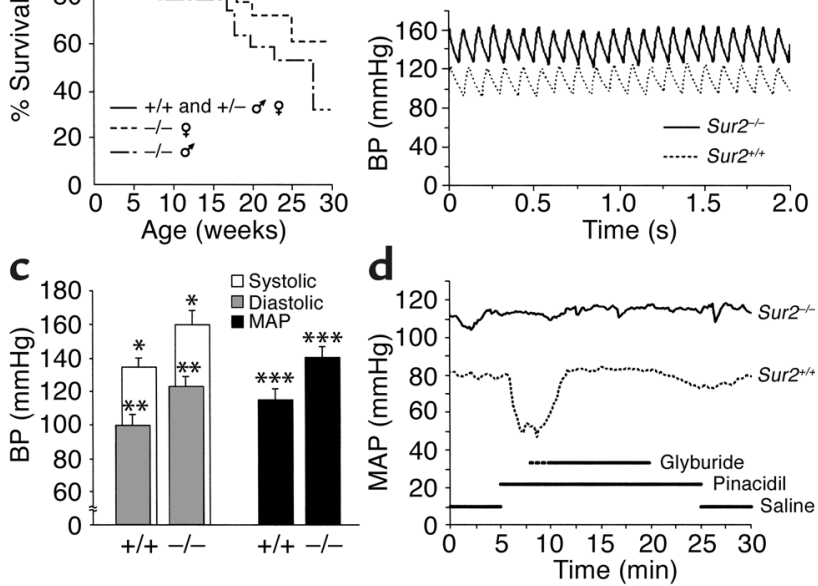

\section{Figure 1}

Cardiovascular physiology in Sur2-/- mice. (a) Sur2 $2^{-/-}$mice exhibit decreased survival. Survival of littermate control and heterozygous mice $\left(\mathrm{Sur}^{+/+} n=15,5\right.$ males and 10 females, and Sur2 ${ }^{+/-}, n=41,12$ males and 29 females), homozygous mutant females (Sur2 ${ }^{-/-}, n=18$ ), and homozygous mutant males (Sur2-/-,$n=17$ ) as a function of age. (b) Telemetric blood pressure recordings of Sur2-/- and normal littermate control mice. Representative blood pressure tracings from conscious, untethered control $\left(\right.$ Sur $\left.2^{+/+}\right)$and homozygous mutant (Sur2 ${ }^{-/}$) mice. (c) Systolic (white bars), diastolic (gray bars), and MAP (black bars) for littermate control and mutant mice $(n=6$ and 4 , respectively), recorded between days 2 and 4 after implantation. ${ }^{*} P<0.04,{ }^{*} P<0.03,{ }^{*} * P<0.02$ versus normal littermate controls by two-tailed, unpaired Student $t$ test. (d) Sur2-/- mice do not respond to $K_{A T P}$ vasoactive agents. Representative MAP tracings from a littermate control mouse (dotted line) and a Sur2 ${ }^{-/-}$mouse (solid line) during infusions of the agents indicated. Pinacidil was administered at $5 \mu \mathrm{g} / \mathrm{kg} / \mathrm{min}$ and glibenclamide at $100 \mu \mathrm{g} / \mathrm{kg} / \mathrm{min}$. The interrupted line for glyburide infusion indicates the beginning of infusion for the normal control mouse $\left(\right.$ Sur $\left.2^{+/+}\right)$, while the mutant mouse $\left(\mathrm{Sur}^{-/-}\right)$infusion begins with the solid line. 


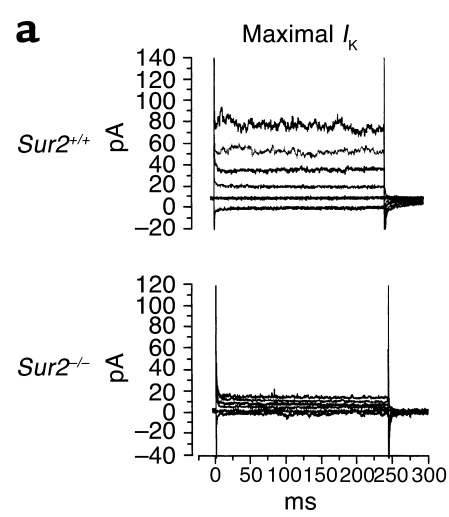

b

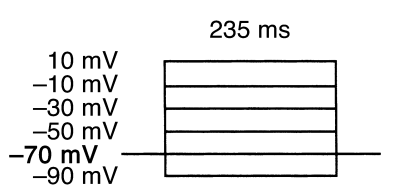

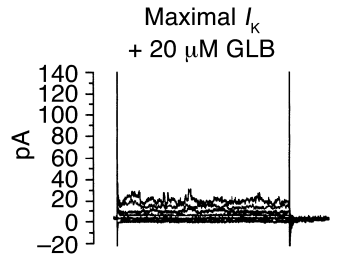
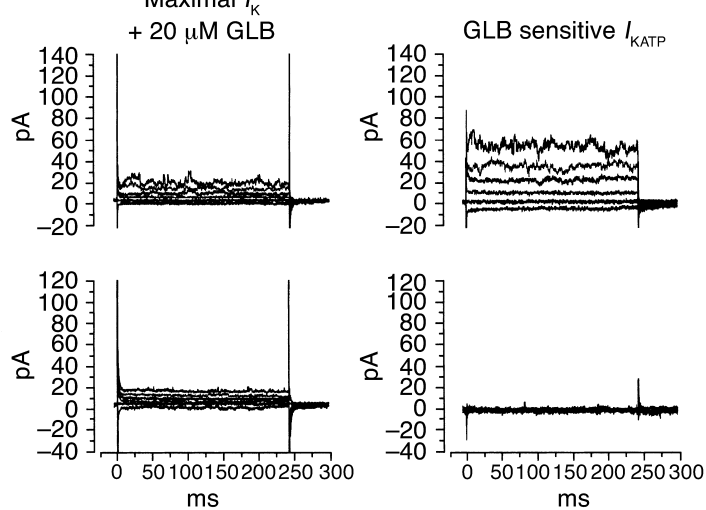

C

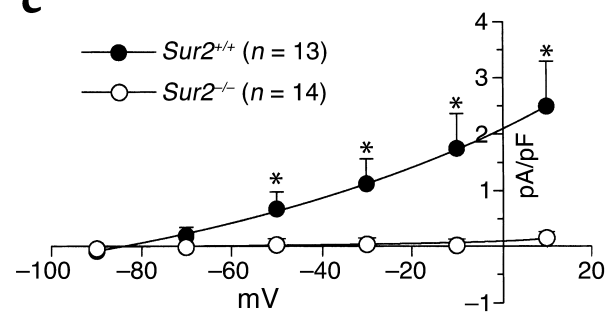

\section{Figure 2}

Absence of K KATP current in aortic smooth muscle cells isolated from Sur2 $2^{-/-}$mice. (a) Examples of original whole cell current traces recorded in a Sur2 $2^{+/+}$and a Sur2 $2^{-/-}$ aortic smooth muscle cell 2 minutes after cell rupture (maximal potassium channel current $\left[I_{K}\right]$, left), after $20 \mu \mathrm{M}$ of glibenclamide (GLB, middle), and the GLB-sensitive $I_{\text {KATP }}$ obtained by subtraction (right). The glibenclamide-sensitive current was interpreted as $\mathrm{K}_{\text {ATP }}$ current and was normalized by cell capacitance to obtain the whole cell current density. The GLB-sensitive current was absent from the Sur2 $2^{-/-}$ cell. (b) Whole cell current protocol. The cell was held at $-70 \mathrm{mV}$, and $235 \mathrm{~ms}$ test pulses from -90 to $10 \mathrm{mV}$ were delivered to induce a whole cell current. (c) Mean summary data of the current voltage plot for the GLB-sensitive $I_{\text {KATP }}$ density at all voltages tested $(n=13$ cells from five Sur $2^{+/+}$mice vs. $n=14$ cells from four Sur2 ${ }^{-/-}$mice, $\left.{ }^{*} P<0.05\right)$.
Extracellular application of pinacidil $200 \mu \mathrm{M}$ (Parke Davis, Ann Arbor, Michigan, USA) could not further increase the current amplitude. The whole cell current could be partially blocked by $20 \mu \mathrm{M}$ glibenclamide (Sigma-Aldrich). The glibenclamide-sensitive current was interpreted as $\mathrm{K}_{\mathrm{ATP}}$ current and was normalized by cell capacitance to obtain the whole cell current density. Current density for each cell was then averaged and compared between $\mathrm{Sur}^{+/+}$and Sur2 $2^{-/-}$mice. The data were expressed as the mean plus or minus SE. A Student $t$ test was used to compare the data between two groups.

Telemetric electrocardiogram monitoring. Electrocardiogram (ECG) recordings were performed in conscious, freely mobile adult mice (12-16 weeks). Implantable radio transmitters (TA11EA-F20; Data Sciences International) were implanted in the subcutaneous tissues of the back while mice were sedated with isoflurane. ECG leads were tunneled subcutaneously to the ventral tho$\operatorname{rax}$ (ECG lead II configuration). Continuous recordings were obtained through the first 3 postoperative days.

Coronary artery Microfil perfusion. Coronary microvasculature perfusion was performed as described (20). After mice inhaled Metofane (Shering-Plough, Kenilworth, New Jersey, USA), a sternotomy exposed the heart. Microfil (1-1.5 ml; FlowTech, Carver, Massachusetts, USA) was injected in the left ventricular apex; heart contractions perfused the coronary microvasculature. The heart was then rapidly excised, cured on ice for 10 minutes, fixed in $10 \%$ formalin for 24 hours, and cleared by sequential 24 -hour immersions in $25 \%, 50 \%$, $75 \%, 95 \%$, and $100 \%$ ethyl alcohol. On day 6 , specimens were placed in methyl salicylate for 12-24 hours.

Subcutaneous drug infusions. Mice were given continuous subcutaneous infusions of either a sham infusate (saline or DMSO) or $3 \mathrm{mg} / \mathrm{kg} / \mathrm{d}$ nifedipine (Sigma-Aldrich)
(21) solubilized in DMSO, using a modified Lynch Coil pump (22). Alzet mini-osmotic pumps (Alza Corp., Mountain View, California, USA) were fitted with a segment of PE-60 polypropylene tube (Becton Dickinson and Co., Sparks, Maryland, USA). The pump and tube were surgically implanted into the subcutaneous tissues of the back. Mice were given a minimum of 8 hours to achieve serum steady state.

\section{Results}

Hypertension and sudden death in Sur2 $2^{-1-}$ mice. In the course of our previous studies on the insulin responsiveness of Sur $2^{--}$mice, we noted sudden, unanticipated death, despite a normal outward appearance and normal basal glucose and serum electrolyte concentrations. By 30 weeks of age, $65 \%$ of the male Sur2 ${ }^{-/}$mice died, as did $35 \%$ of Sur2 ${ }^{-/}$females (Figure 1a). Because potassium channel openers have a role in lowering blood pressure, we evaluated vascular tone in Sur2-- mice with continuous, telemetrically recorded blood pressure monitoring of conscious 12- to 18-week-old Sur2 ${ }^{+/+}$and Sur2 $2^{-/-}$mice (Figure 1, b and c). Sur2 ${ }^{-/-}$mice exhibited significantly elevated systolic and diastolic blood pressures of 161/122 mmHg when compared with normal control littermates, which had blood pressures of $135 / 100 \mathrm{mmHg}(n=4$ and 6 , respectively; $P<0.04)$. Mean arterial blood pressure (MAP) was similarly elevated, $140 \pm 6.4 \mathrm{mmHg}$ for Sur2 $2^{--}$ compared with $115 \pm 5.2 \mathrm{mmHg}$ for normal Sur $2^{+/+}$mice. Anesthetized blood pressure recordings were taken during intravenous application of $\mathrm{K}_{\mathrm{ATP}}$-activating and inhibiting compounds (Figure $1 \mathrm{~d}, n=3$ ). Pinacidil elicited a significant blood pressure drop in normal littermate control mice, while the coadministration of the sulfonylurea glyburide inhibited the pinacidil response to restore baseline blood pressures. Sur $2^{-/-}$mutant mice did not 


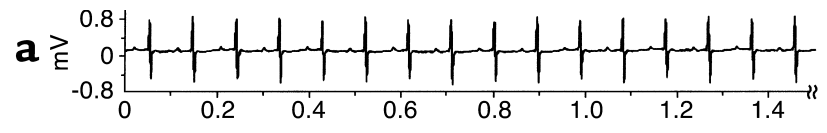

b

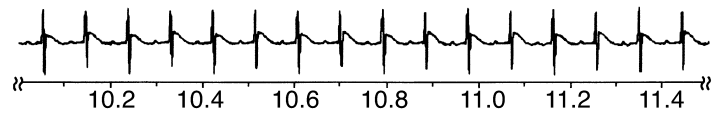

C

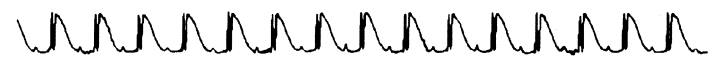

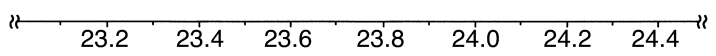

d

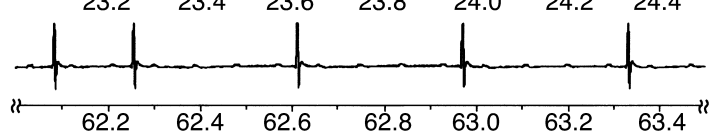

e
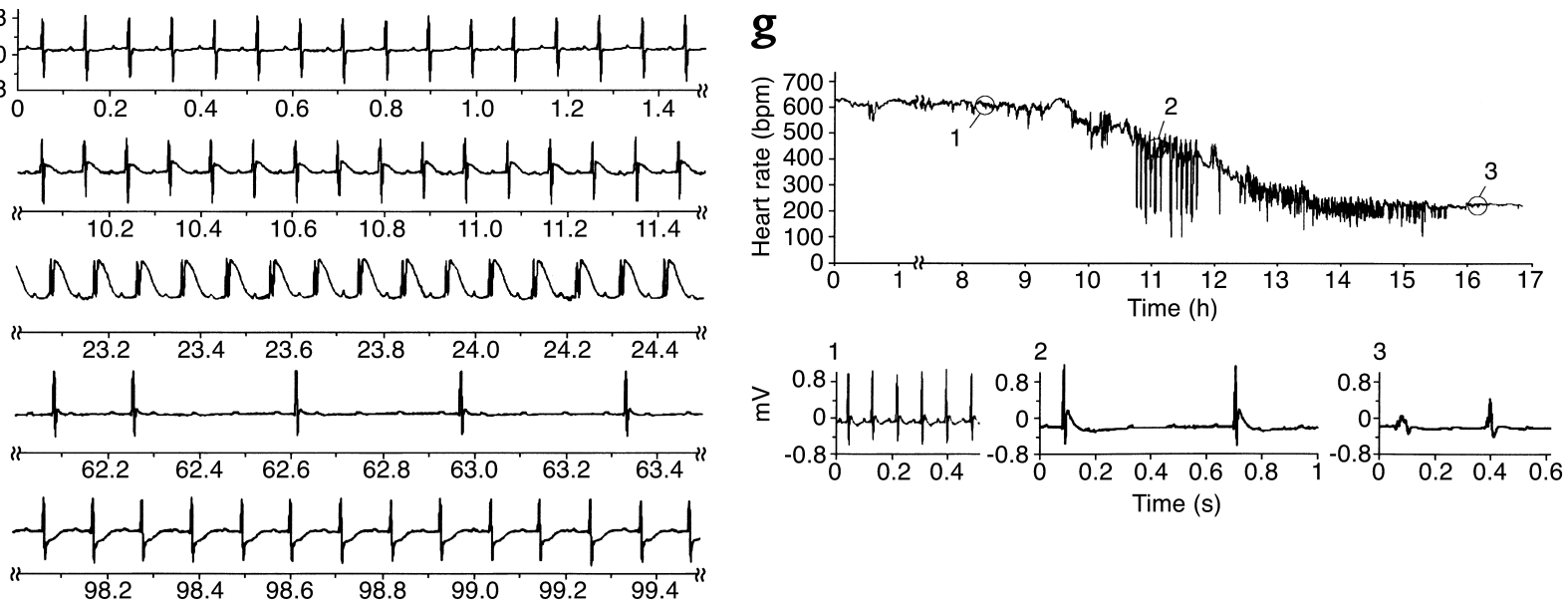

f

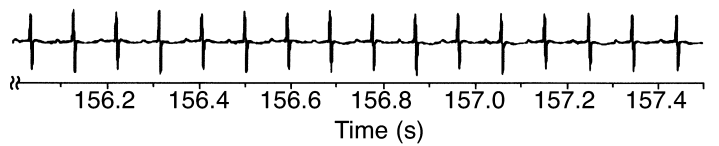

Figure 3

In vivo evidence of coronary artery vasospasm in Sur2-/- mice. (a-f) Representative telemetric ECG recording of a 12-week-old male Sur2-/mouse. Each of the serial tracings reflects 1.5 seconds of the entire 160 -second episode. The timing of each 1.5 -second segment with respect to the duration of the entire episode is indicated in seconds below the tracing. (a) A baseline tracing at the beginning of the event. (b and $\mathbf{c}$ ) Marked ST segment elevation that occurs within 30 seconds. ST segment elevation leads to atrioventricular heart block seen in d. Following the acute injury pattern of ST segment elevation, ST segment depression was present during recovery (e). (f) A return to baseline ECG readings. (g) Continuous ECG recording capturing sudden death. Upper tracing depicts heart rate and bradycardia events (downward spikes) over a 17-hour period. Individually, numbered regions are magnified in the lower three sets of ECG waveform tracings indicating: 1, normal rate and rhythm; 2, post-ST elevation atrioventricular heart block with bradycardia; 3, agonal rhythm with a widened QRS.

experience a drop in blood pressure with the application of pinacidil, nor did they demonstrate any response to glyburide, consistent with the loss of smooth muscle SUR2 $\mathrm{K}_{\text {ATP }}$ channel activity. Despite elevated systemic blood pressures, histologic analysis of Sur2 ${ }^{-/-}$hearts (age 12-16 weeks) showed no obvious differences from normal mice (data not shown).

Absent smooth muscle $K_{\text {ATP }}$ channels. Electrophysiologic patch clamp recordings on isolated aortic smooth muscle cells from Sur2 $2^{-/}$and Sur2 $2^{++}$mice (Figure 2) demonstrated the absence of SUR $2 \mathrm{~K}_{\mathrm{ATP}}$ channels. The average cell capacitance was $8.03 \pm 0.73 \mathrm{pF}$ for $\mathrm{Sur}^{+/+}$ mice and $7.74 \pm 0.76 \mathrm{pF}$ for Sur2 $2^{-/-}$mice $(P<0.05)$. Immediately after membrane rupture, an increase of whole cell current was seen in Sur2 ${ }^{+/+}$cells, but was absent in Sur2 ${ }^{-/-}$cells (Figure 2a). Extracellular application of $20 \mu \mathrm{M}$ glibenclamide partially blocked this increase of whole cell current in Sur2 $2^{+/+}$smooth muscle cells, demonstrating that this current reflects SUR2 function (Figure 2a). At all voltages tested, typical voltage-dependent and glibenclamide-sensitive $\mathrm{K}_{\mathrm{ATP}}$

\section{Figure 4}

Coronary artery vasospasm. The coronary vasculature was perfused with Microfil, a liquid latex medium, as described previously (20). Microvascular perfusion was visualized by transillumination under low-power magnification. (upper left panel) Normal microvasculature of a littermate control male mouse. (upper right panel and lower panels) Examples of focal artery stenoses in three Sur2 ${ }^{-/-}$mice. Arrows indicate significant coronary artery stenoses. current was seen in Sur2 ${ }^{+/+}$cells, but was absent in Sur $2^{-/-}$cells. The current was outward under physiological potassium concentration $\left(4_{\text {out }} / 140_{\text {in }}\right)$ and reversed at $-87 \mathrm{mV}$, near the theoretical value of -89 $\mathrm{mV}$ for $\mathrm{K}^{+}$(Figure 2, $\mathrm{b}$ and $\mathrm{c}$ ). The current density at a test pulse of $-10 \mathrm{mV}$ was $1.72 \pm 0.64 \mathrm{pA} / \mathrm{pF}$ in $\mathrm{Sur}^{+/+}$ cells and only $0.04 \pm 0.04 \mathrm{pA} / \mathrm{pF}$ in Sur2 $2^{-/}$cells $(P<0.01)$. From these studies, we conclude that the glibenclamide-sensitive $K_{\text {ATP }}$ current was indeed absent in the Sur2-/- vascular smooth muscle.

Coronary artery vasospasm. Early sudden death in Sur2 ${ }^{-/}$mice suggested cardiac arrhythmias. We investigated this possibility in Sur2-/- animals using continuous telemetric ECG recording. Baseline resting heart
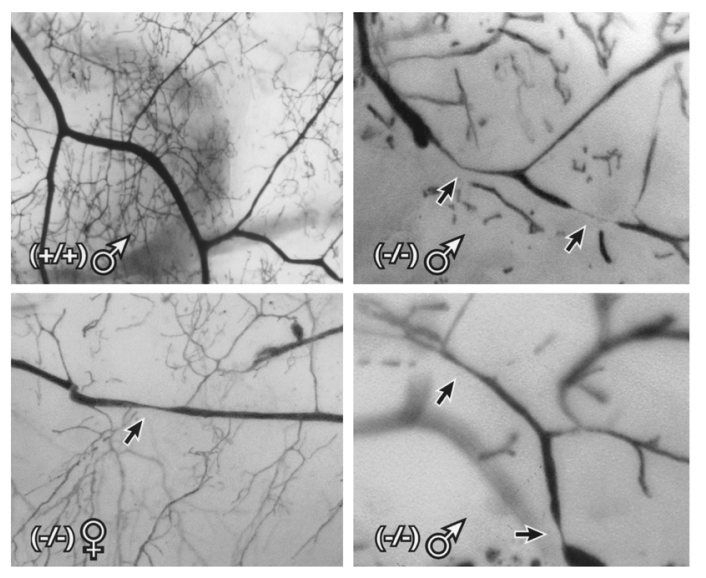


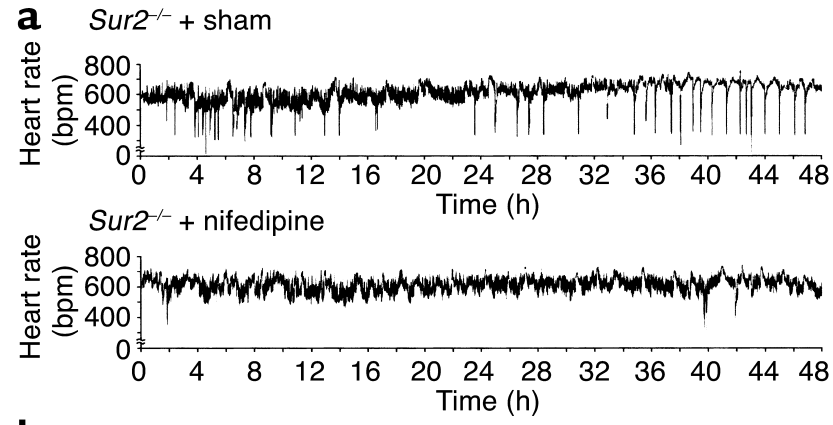

b

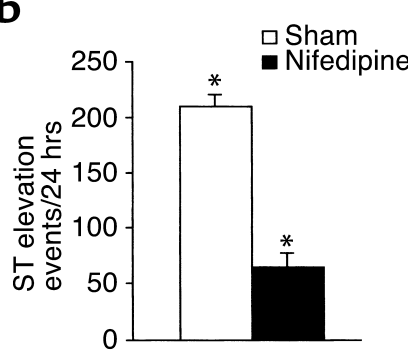

c
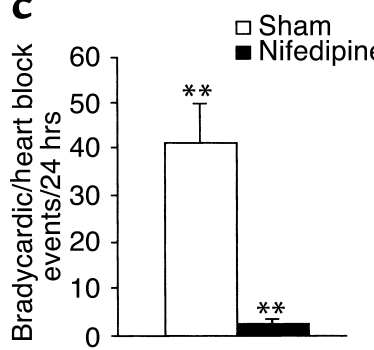

Figure 5

Successful treatment of coronary artery vasospasm in Sur2-/- mice with nifedipine. (a) Representative continuous ECG recordings obtained during subcutaneous infusion of a sham-infusate (saline or DMSO) versus nifedipine at $3 \mathrm{mg} / \mathrm{kg} / \mathrm{d}$. Tracings depict heart rate, with sharp downward deflections representing deceleration in the heart rate or episodic bradycardia. Graphic summary of quantitative decrease of (b) ST segment elevation events per 24-hour period, and (c) heart block episodes per 24-hour period ( $n=5$ each). White bars represent sham-infusate group. Black bars represent nifedipine group. ${ }^{*}{ }^{*} P<0.0001$ by two-tailed, unpaired Student $t$ test.

rates, PR intervals, and QRS morphology were similar between Sur2 ${ }^{-/-}$mice and normal littermate controls (Figure 3a.) However, both male and female Sur2 ${ }^{-/-}$mice exhibited repeated episodes of spontaneous ST segment elevation (Figure 3, b and c). Frequently, ST segment episodes were followed by slow heart rates, typically the consequence of atrioventricular heart block (Figure 3d). ST segment depression, a marker of global myocardial ischemia, was noted during the recovery phase of these transient ischemic events (Figure 3e). A number of recordings captured Sur $2^{-/-}$moribund events, and an example is shown in Figure $3 \mathrm{~g}$. Death occurred from a rapid sequence of ST segment elevation followed by prolonged atrioventricular heart block and asystole (Figure $3 \mathrm{~g})$. Only normal baseline ECG tracings were seen in littermate control mice, and no littermate control mice died during monitoring. The pattern of ST segment elevation ECG changes observed in the Sur2 ${ }^{-/-}$mice is identical to that seen in Prinzmetal or variant angina, a human disorder associated with chest pain and sudden death stemming from coronary artery vasospasm (23). While arrhythmias are commonly noted in Prinzmetal patients, in humans arrhythmias may be due to tachyarrhythmias or bradyarrhythmias.

To demonstrate spontaneous vasospasm as an underlying cause of the episodic ECG changes and sudden death, we perfused the coronary arteries of mice with latex Microfil as described (20). The coronary arteries of littermate control male mice were normally distributed and smoothly tapered, with an occasional focal tapering (Figure 4, upper left). In contrast, every Sur $2^{-/-}$ mouse studied showed evidence of arterial stenoses (Figure 4). Coronary vasculature constrictions seen in Sur $2^{-/-}$mice represent the anatomic correlate of ST segment changes and spontaneous vasospasm.

Inhibition of coronary artery vasospasm with calcium channel antagonists. Resting membrane potential modulated by $\mathrm{K}_{\text {ATP }}$ channel activity directly alters calcium channel function. Because calcium channel antagonists suppress spontaneous vasospasm and subsequent myocardial ischemia, they are used to treat Prinzmetal variant angina (24). Telemetric ECG monitoring was repeated in Sur $2^{-/-}$male mice after a continuous infusion of the calcium channel antagonist nifedipine. Sur $2^{-/-}$mice receiving a $3 \mathrm{mg} / \mathrm{kg} / \mathrm{d}$ nifedipine infusion had a marked reduction in the number of ST segment elevations in the first 48 hours of ECG recording $(210 \pm 11$ events/d in sham-infused vs. $66 \pm 12$ events/d in nifedipine-infused mice; $P<0.0001$ ) (Figure $5 b)$. Furthermore, the nifedipine-treated group experienced a significant reduction in the number of heart block/bradycardia events over 48 hours compared with the sham-infused group ( $41.0 \pm 9$ vs. $2.6 \pm 0.9 ; P<0.002)$. These findings emphasize the downstream role of calcium channels with respect to $K_{\text {ATP }}$ activity (23).

\section{Discussion}

The presence of hypertension and vasospasm in Sur2-/mice reveals a pivotal role for smooth muscle $\mathrm{K}_{\mathrm{ATP}}$ channels in the overall regulation of vascular tone. SUR2 $\mathrm{K}_{\mathrm{ATP}}$ channel-deficient mice develop increased vascular tone consistent with essential hypertension. In addition to this tonic increase in vasomotor tone, the absence of $\mathrm{K}_{\mathrm{ATP}}$ channels promotes episodic vasospasm. Episodic alterations in vascular tone result from a shift in the balance of vasodilatory and vasoconstrictive cues. A number of metabolic and humoral vasoactivators have been suggested to modulate $\mathrm{K}_{\mathrm{ATP}}$ channels. Examples of vasodilating agents that act through $K_{A T P}$ channels include nitric oxide, adenosine, calcitonin gene-related peptide, neuropeptide $Y$, prostacyclin, adrenergic stimuli, and metabolic changes associated with hypoxia (14, $15,25-28)$. $\mathrm{K}_{\mathrm{ATP}}$-associated vasoconstrictors include thromboxane A2 and endothelin (29). Because of the absence of vascular $\mathrm{K}_{\mathrm{ATP}}$ channels, factors that usually do not elicit vasoconstriction in the presence of normal $K_{\text {ATP }}$ channel activity may now be unopposed in Sur $2^{-/-}$mice.

We showed previously an absence of myocardial SUR2 $\mathrm{K}_{\text {ATP }}$ channels in Sur2-/- mice (16), and here we show that ST segment elevation occurs in the absence of SUR2. $\mathrm{K}_{\mathrm{ATP}}$ channels have been implicated previously in the generation of ST segment elevation (30). Kir6.2 null mice have attenuated ST segment elevation after 5 minutes of ischemia. In Sur2 $2^{-/}$mice, episodes of ST segment elevation are brief, 30-60 seconds. Thus, early ST segment elevation may be mediated by alternative channel activity or, in Sur $2^{-/-}$cardiomyocytes, Kir6.2 
may couple with an alternative regulatory subunit capable of mediating ST segment elevation.

$\mathrm{K}_{\text {ATP }}$ channels have been identified as important mediators of ischemic preconditioning where intermittent exposure to hypoxic conditions limits ischemic damage (31). Potassium channel-opening agents stimulate ischemic preconditioning via their action on $\mathrm{K}_{\mathrm{ATP}}$ channels. The precise mechanism by which ischemic preconditioning occurs is unknown, although it has been suggested to involve mitochondrial $\mathrm{K}_{\mathrm{ATP}}$ channels. It may be expected that the repeated instances of vasospasm coupled with the loss of $\mathrm{K}_{\mathrm{ATP}}$ channels in the myocardium would render Sur $2^{-/-}$mice more susceptible to ischemic damage. We did not observe histological evidence of myocardial ischemia or infarction in hearts from Sur2-/mice (not shown). The brevity of the coronary artery vasospastic episodes may be insufficient to generate a prolonged interval of ischemic damage necessary to cause histologic changes. Alternatively, the arrhythmic episodes that result from coronary artery vasospasm may lead to death before the development of myocardial infarction.

Our results demonstrate that SUR2-K $K_{\text {ATP }}$ channels serve as key modulators of vascular smooth muscle activity regulating blood pressure and episodic coronary artery tone. This work identifies an important pharmacologic target for the treatment of hypertension and vasospasm. Our findings suggest that SUR2 plays a critical role in clinically defined human illnesses, namely essential hypertension and Prinzmetal angina, as well as the vasospasm frequently associated with atherosclerotic coronary artery disease. Finally, because antihyperglycemic sulfonylurea agents close SUR2 $\mathrm{K}_{\mathrm{ATP}}$ channels with low affinity, these data raise the possibility that their use may increase susceptibility to vasospasm. Some epidemiologic studies of sulfonylurea agents in diabetics have found an increase in cardiovascular events, while others have not (32). In light of the data now presented, further studies are warranted.

Note added in proof: T. Miki et al. recently reported similar findings in mice lacking Kir6.1, the partner protein of SUR2 (2002. Mouse model of Prinzmetal angina by disruption of the inward rectifier Kir6.1. Nat. Med. 8:466-472).

\section{Acknowledgments}

This work was supported by a pilot project award from an NIH Diabetes Research and Training grant, the American Heart Association, and the Burroughs Wellcome Fund (to E.M. McNally), and by NIH grant HL-57414 (to J.C. Makielski).

1. Noma, A. 1983. ATP-regulated $\mathrm{K}+$ channels in cardiac muscle. Nature. 305: $147-148$.

2. Ashcroft, S.J., and Ashcroft, F.M. 1990. Properties and functions of ATPsensitive K-channels. Cell Signal. 2:197-214.

3. Inagaki, N., et al. 1995. Reconstitution of IKATP: an inward rectifier subunit plus the sulfonylurea receptor. Science. 270:1166-1170.

4. Inagaki, N., et al. 1995. Cloning and functional characterization of a novel ATP-sensitive potassium channel ubiquitously expressed in rat tissues, including pancreatic islets, pituitary, skeletal muscle, and heart. J. Biol. Chem. 270:5691-5694.
5. Aguilar-Bryan, L., et al. 1995. Cloning of the beta cell high-affinity sulfonylurea receptor: a regulator of insulin secretion. Science. 268:423-426. 6. Chutkow, W.A., Simon, M.C., Le Beau, M.M., and Burant, C.F. 1996 Cloning, tissue expression, and chromosomal localization of SUR2, the putative drug-binding subunit of cardiac, skeletal muscle, and vascular KATP channels. Diabetes. 45:1439-1445.

7. Inagaki, N., et al. 1996. A family of sulfonylurea receptors determines the pharmacological properties of ATP-sensitive K+ channels. Neuron. 16:1011-1017.

8. Isomoto, S., et al. 1996. A novel sulfonylurea receptor forms with BIR (Kir6.2) a smooth muscle type ATP-sensitive $\mathrm{K}+$ channel. J. Biol. Chem. 271:24321-24324.

9. Clement, J.P., et al. 1997. Association and stoichiometry of K(ATP) channel subunits. Neuron. 18:827-838.

10. Sakura, H., Trapp, S., Liss, B., and Ashcroft, F.M. 1999. Altered functional properties of KATP channel conferred by a novel splice variant of SUR1. J. Physiol. 521:337-350.

11. Chutkow, W.A., Makielski, J.C., Nelson, D.J., Burant, C.F., and Fan, Z. 1999. Alternative splicing of sur2 exon 17 regulates nucleotide sensitivity of the ATP-sensitive potassium channel. J. Biol. Chem. 274:13656-13665.

12. Samaha, F.F., Heineman, F.W., Ince, C., Fleming, J., and Balaban, R.S. 1992. ATP-sensitive potassium channel is essential to maintain basal coronary vascular tone in vivo. Am. J. Physiol. 262:C1220-C1227.

13. Nelson, M.T., Patlak, J.B., Worley, J.F., and Standen, N.B. 1990. Calcium channels, potassium channels, and voltage dependence of arterial smooth muscle tone. Am. J. Physiol. 259:C3-C18.

14. Daut, J., et al. 1990. Hypoxic dilation of coronary arteries is mediated by ATP-sensitive potassium channels. Science. 247:1341-1344.

15. Quayle, J.M., Nelson, M.T., and Standen, N.B. 1997. ATP-sensitive and inwardly rectifying potassium channels in smooth muscle. Physiol. Rev. 77:1165-1232.

16. Chutkow, W.A., et al. 2001. Disruption of Sur2-containing KATP channels enhances insulin-stimulated glucose uptake in skeletal muscle. Proc. Natl. Acad. Sci. USA. 98:11760-11764.

17. Sturek, M., Kunda, K., and Hu, Q. 1992. Sarcoplasmic reticulum buffering of myoplasmic calcium in bovine coronary artery smooth muscle. J. Physiol. 451:25-48.

18. Hamill, O.P., Marty, A., Neher, E., Sakmann, B., and Sigworth, F.J. 1981 Improved patch-clamp techniques for high-resolution current recording from cells and cell-free membrane patches. Pflugers Arch. 391:85-100.

19. Yamada, M., et al. 1997. Sulphonylurea receptor 2B and Kir6.1 form a sulphonylurea-sensitive but ATP-insensitive $\mathrm{K}+$ channel. J. Physiol. (Lond). 499:715-720.

20. Coral-Vazquez, R., et al. 1999. Disruption of the sarcoglycan-sarcospan complex in vascular smooth muscle: a novel mechanism for cardiomyopathy and muscular dystrophy. Cell. 98:465-474.

21. Hirata, A., et al. 2000. Nifedipine suppresses neointimal thickening by its inhibitory effect on vascular smooth muscle cell growth via a MEKERK pathway coupling with Pyk2. Br. J. Pharmacol. 131:1521-1530.

22. Lynch, H.J., Rivest, R.W., and Wurtman, R.J. 1980. Artificial induction of melatonin rhythms by programmed microinfusion. Neuroendocrinology. 31:106-111.

23. Mayer, S., and Hillis, L.D. 1998. Prinzmetal's variant angina. Clin. Cardiol. 21:243-246.

24. Morikami, Y., and Yasue, H. 1991. Efficacy of slow-release nifedipine on myocardial ischemic episodes in variant angina pectoris. Am. J. Cardiol. 68:580-584.

25. Nelson, M.T., Huang, Y., Brayden, J.E., Hescheler, J., and Standen, N.B. 1990. Arterial dilations in response to calcitonin gene-related peptide involve activation of $\mathrm{K}+$ channels. Nature. 344:770-773.

26. Quayle, J.M., and Standen, N.B. 1994. KATP channels in vascular smooth muscle. Cardiovasc. Res. 28:797-804.

27. Tanaka, E., et al. 1997. Coronary vasoconstrictive effects of neuropeptide $\mathrm{Y}$ and their modulation by the ATP-sensitive potassium channel in anesthetized dogs. J. Am. Coll. Cardiol. 29:1380-1389.

28. Narishige, T., et al. 1993. Glibenclamide, a putative ATP-sensitive K+ channel blocker, inhibits coronary autoregulation in anesthetized dogs. Circ. Res. 73:771-776.

29. Shepherd, J.T., and Katusic, Z.S. 1991. Endothelium-derived vasoactive factors. I. Endothelium-dependent relaxation. Hypertension. 18(Suppl. 5):III76-85

30. Li, R.A., Leppo, M., Miki, T., Seino, S., and Marban, E. 2000. Molecular basis of electrocardiographic ST-segment elevation. Circ. Res. 87:837-839.

31. Cohen, M.V., Baines, C.P., and Downey, J.M. 2000. Ischemic preconditioning: from adenosine receptor of KATP channel. Annu. Rev. Physiol. 62:79-109.

32. Brady, P.A., and Terzic, A. 1998. The sulfonylurea controversy: more questions from the heart. J. Am. Coll. Cardiol. 31:950-956. 